\title{
A CONDIÇÃo DE ATINGIDO POR BARRAGEM: ELEMENTOS PARA UMA ABORDAGEM CONCEITUAL
}

\section{THE DAM AFFECTED CONDITION: ELEMENTS FOR A CONCEPTUAL APPROACH}

\author{
Humberto José da Rocha ${ }^{1}$ \\ https://orcid.or/0000-0001-9943-9125
}

Submissão: 02/02/2021 / Aceito: 05/04/2021 / Publicado: 13/08/2021

\begin{abstract}
Resumo
Este artigo tem como objetivo geral apresentar elementos para uma abordagem conceitual sobre o tema dos atingidos por barragens. Metodologicamente, procura relacionar as perspectivas teórica, a partir de revisão bibliográfica, e empírica, mediante pesquisa realizada quando da instalação da UHE Foz do Chapecó, na bacia hidrográfica do Uruguai, no sul do Brasil. Dessa relação, defende-se a tese de compreensão sobre "atingido por barragem" enquanto uma "condição", marcada pela transitoriedade e a ser construída em cada hidrelétrica em sua especificidade e em relação a um processo social amplo.
\end{abstract}

Palavras-chave: Atingidos por barragens. Condição social. Conflito social.

\begin{abstract}
This article has as general objective to present elements for a conceptual approach on the subject of those affected by dams. Methodologically, it seeks to relate the theoretical perspectives, based on bibliographic review, and empirical, through research carried out when the installation of the Foz do Chapecó HPP, in the hydrographic basin of Uruguay, in southern Brazil. From this relationship, the thesis of understanding about "Dam Affected" is defended as a "condition", marked by transience and to be built in each hydroelectric in its specificity and in relation to a broad social process.
\end{abstract}

Keywords: Dams affected. Social condition. Social conflict.

\section{INTRODUÇÃ̃o}

Desde a primeira Usina Hidrelétrica de Energia (UHE) instalada no Brasil, em Minas Gerais (1883), até as mais recentes, pode-se perceber um processo histórico que apresenta especificidades em cada nova hidrelétrica a ser instalada, refletindo na complexidade da questão em diferentes campos, seja técnico, econômico, político, jurídico ou ambiental.

Do ponto de vista da discussão sobre o conceito de atingido, pode-se notar uma evolução, mesmo que tímida, no sentido da ampliação do conceito. Com o propósito de subsidiar essa

\footnotetext{
${ }^{1}$ Doutor em Ciências Sociais pela Unicamp. Professor no Programa de Pós-Graduação em História da Universidade Federal da Fronteira Sul.
}

DOI: https://doi.org/10.46699/rduno.v4i5.6050 | Edição Vol. 4, Núm. 5, 2021. 
discussão, Carlos Vainer escreveu, ainda em 2003, um trabalho fundamental que passou por revisões (VAINER, 2008; 2012) e mantém-se como a principal referência sobre o tema no Brasil. O autor apresenta diferentes conceitos tanto das agências, organizações e legislações, quanto de trabalhos acadêmicos, a partir do que é possível perceber como uma evolução que, incialmente, considerava como atingidos apenas os proprietários de terras a serem inundadas pelos lagos das barragens. As exigências de agências como o Banco Mundial, o avanço da legislação ambiental e as lutas sociais, fizeram com que o conceito de atingido fosse sendo ampliado espacial e temporalmente ao longo desse processo.

Ainda que se registre essa evolução no conceito de atingido, o que implica reconhecimento dos direitos dessas populações, não se pode tratar a questão de maneira homogênea. Considerando o processo de expansão hidrelétrica no Brasil (MORETTO et al., 2012; OLIVEIRA, 2018), desde as primeiras iniciativas no sudeste e centro-sul até a intensificação da exploração na bacia amazônica, é possível verificar a evolução de um processo continuo de acumulação ampliada de capital que recebe elementos diferentes em cada nova hidrelétrica. Do ponto de vista sociológico, aproxima-se do que José de Souza Martins trata no âmbito de uma "frente de expansão", no sentido amplo do território nacional, que produz "situações de fronteira" nos pontos onde se encontram grupos com interesses conflitivos, nesse caso, a hidrelétrica em questão, que, por sua riqueza de possibilidades, seria privilegiada enquanto objeto de pesquisa (MARTINS, 1997).

Tomando como exemplo a bacia hidrográfica do Uruguai, no sul do Brasil, se adotarmos como referência temporal a década de 1990 como intensificação da exploração hidrelétrica², percebe-se que, desde as UHEs Itá e Machadinho, sob execução da Eletrosul e, posteriormente, sob regime de Parceria Público-Privada, até as UHEs Barra Grande, Campos Novos e Foz do Chapecó, para mencionar apenas as maiores, identifica-se um acúmulo de experiências paralelamente a inovações nas relações entre os grupos em conflito que permitem uma variedade de análises e argumentos no que tange ao conceito de atingido. No que diz respeito às organizações, agências e legislações, o conceito de atingido tem-se alterado em função de cada Termo de Acordo firmado entre os Grupos em cada hidrelétrica a ser instalada. Já nos trabalhos acadêmicos, especialmente nessa região sul do Brasil, percebem-se diferentes perspectivas de entendimento, assinalando tanto um viés negativo, sintetizado em ideias como "refugiados" (BARON, 2012; NÓBREGA, 2011) ou “vítimas do desenvolvimento" (RENK; WINCKLER, 2016); quanto num sentido positivo,

\footnotetext{
${ }^{2}$ Sem desconsiderar os estudos do potencial hidrelétrico realizados ainda na década de 1960 pelo CANAMBRA e a operação da UHE Passo Fundo desde no início da década de 1970.
}

DOI: https://doi.org/10.46699/rduno.v4i5.6050 | Edição Vol. 4, Núm. 5, 2021. 
destacando um "crescimento econômico e patrimonial" (BOAMAR, 2003), caracterizando os atingidos como "majoritariamente satisfeitos" (PASE; LINHARES; MATOS, 2014) ou mesmo "beneficiários" de uma "melhora na qualidade de vida" (BORGES, 2015), o que aponta para a diversidade e complexidade dos fatos a serem considerados nessa discussão ${ }^{3}$.

As abordagens mencionadas anteriormente ilustram diferentes perspectivas teóricas, metodológicas e de interpretação, algumas delas, inclusive, analisam as mesmas hidrelétricas, o que corrobora a complexidade do tema e inscreve a questão da condição de atingido enquanto um "fato social total", no sentido apresentado por Marcel Mauss. ${ }^{4}$ No estudo de 1923, sobre as trocas nas sociedades arcaicas da Polinésia, Melanésia e noroeste americano, o autor propõe a análise de conjuntos de fatos que, por sua complexidade, "põem em ação, em certos casos, a totalidade da sociedade e de suas instituições e, noutros casos, somente um número muito grande de instituições”, o que o autor complementa afirmando que "esses fenômenos são ao mesmo tempo jurídicos, econômicos, religiosos, e mesmo estéticos, morfológicos etc" (MAUSS, 2003, p. 309). Todavia, essa confluência de fatos de diferentes ordens pode significar tanto a virtude quanto o problema da análise. Na introdução sobre trabalhos de Mauss, Claude Lévi-Strauss adverte que

\footnotetext{
a única garantia que podemos ter de que um fato total corresponde à realidade, em vez de ser o acúmulo arbitrário de detalhes mais ou menos verídicos, é que ele seja apreensível numa experiência concreta: primeiro, de uma sociedade localizada no espaço ou no tempo, 'Roma, Atenas'; mas também de um indivíduo qualquer de alguma dessas sociedades, 'o melanésio dessa ou daquela ilha' (LÉVI-STRAUSS, 2003, p. 24).
}

Isto posto, na medida em que se aprofunda o estudo sobre as hidrelétricas, reforça-se a ideia da condição de atingido por barragem como um fato social total, ao passo em que se acolhe a preocupação metodológica de Lévi-Strauss relacionando o conceitual com a realidade concreta representada no espaço-tempo pelo processo de instalação de uma hidrelétrica em determinada região, onde os indivíduos envolvidos, por excelência, são os atingidos por barragens.

Assim sendo, este trabalho baseia-se em pesquisas sobre a questão dos atingidos por barragens dividindo o argumento em três partes: a) primeiro, apresentando as linhas gerais do que se entende pelo termo e qual sua relação com a ideia de identidade, frequente nas discussões que abordam disputas entre atores sociais; b) segundo, entendendo o termo como uma construção social que se dá a partir de relações de poder ao longo de um processo social amplo, que sofre alterações

\footnotetext{
${ }^{3}$ Ver Borges (2020) para uma compilação de perspectivas conceituais.

4 Agradeço a contribuição da professora Arlene Renk, que numa troca de mensagens sobre a escrita desse trabalho, chamou a atenção para a possibilidade de abordagem da questão da condição de atingido nesse sentido.
}

DOI: https://doi.org/10.46699/rduno.v4i5.6050 | Edição Vol. 4, Núm. 5, 2021. 
menores, em cada caso específico, ou seja, em cada nova hidrelétrica; e c) terceiro, discutindo a transitoriedade do termo procurando entender de que forma a condição de atingido é temporalmente preponderante na medida em que as UHEs têm momentos distintos - que aqui serão tomados como antes da LI (Licença de Instalação), durante a LI (ou entre a LI e a LO [Licença de Operação]), e depois da LI (quando a LO autoriza o funcionamento da usina).

As linhas gerais sobre a condição de atingido por barragem, bem como os atributos de construção e transitoriedade, suscitam a discussão de um termo vital na questão da hidreletricidade no aspecto sociológico. Entende-se a hidreletricidade enquanto um processo social amplo com especificidades em cada nova hidrelétrica instalada. Optou-se por orientar a discussão a partir de uma realidade específica, o caso da UHE Foz do Chapecó, na bacia do rio Uruguai, a partir do que se propõe não um conceito definitivo sobre atingidos por barragens, mas elementos que ajudam a conformar uma conceituação levando em consideração os casos específicos.

\section{A CONDiÇÃo de ATINGIDO POR BARRAGEM}

Tudo com o que o homem toma contato ao longo de sua existência, seja alheio à sua vontade ou seja por ele produzido, passa a compor, de alguma forma, a sua "condição humana". As atividades biológicas ("labor"), de produção de coisas artificiais ("trabalho"), e de relação política com outros homens ("ação") - entre outras como a razão e o pensamento -, compõem essa condição, sem que se possa apontar um único elemento que, por si só, seja essencial para tal condição, nem tampouco que os homens sejam condicionados de forma absoluta por qualquer um desses elementos (ARENDT, 2005).

Do ponto de vista sociológico, pode-se tomar o conceito de "condição social" como sendo o "conjunto de circunstâncias e dos acontecimentos que fazem com que uma pessoa ou um grupo ocupem determinada situação ou determinada posição na sociedade" (BIROU, 1973, p. 77). Procurando adequar o conceito genérico à especificidade deste trabalho, essas "circunstâncias e acontecimentos" serão aqui tratados como variáveis que possibilitam vislumbrar o que pode ser compreendido como atingido por barragem em determinado caso. Essas variáveis precisam ser percebidas em seu sentido mais restrito, ou seja, nunca podem ser tomadas como algo estático, predefinido. Elias (2000, p. 53), ao estudar uma comunidade de trabalhadores ingleses, esclarece que as impressões colhidas na sua pesquisa "não podiam ser explicadas por meio de métodos voltados para a medição de 'fatores' ou 'variáveis', como se cada um deles existisse e pudesse variar por si, independente da configuração social completa". Transportando essa consideração do autor 
para o caso das hidrelétricas, pode-se dizer que as variáveis - mesmo aquelas mais gerais - precisam ser consideradas na configuração estabelecida em cada caso.

Considerando que as hidrelétricas alteram significativamente a configuração social do local onde são instaladas (RIBEIRO, 1999, p. 109), para a compreensão do termo atingido, num determinado caso, é preciso empreender um exercício de relação entre as diferentes variáveis identificadas no referido caso. Assim sendo, seguindo as orientações de Bourdieu (2009a, p. 29-32), propõe-se a construção de um quadro de variáveis que serão relacionadas com indivíduos e grupos, de forma a visualizar algumas das possibilidades da condição de atingido por barragem.

A elaboração do quadro neste trabalho (Figura 1) procurou considerar as diferentes variáveis apresentadas em casos estudados em todo o Brasil. Porém, como já foi expresso, para tomar um ponto de referência, e até por conhecimento da região, priorizou-se o Alto Uruguai (Bacia do rio Uruguai) como parâmetro para a relação das variáveis e seus desdobramentos. Esse registro é importante para manifestar o esclarecimento de que se admite a exclusão, inserção ou sobreposição de variáveis de acordo com o caso a que se apliquem.

O quadro a seguir foi elaborado tendo em vista a condição de atingido no aspecto coletivo (aldeias indígenas, comunidades quilombolas, vilas, cidades) e no aspecto individual, por entenderse que, mesmo dentro de um grupo, seja possível que as variáveis condicionem as pessoas de formas distintas, tanto que se optou por apresentar algumas das variáveis identificadas em diferentes casos, que reforçam a complexidade do conceito. Embora a maioria das variáveis e seus desdobramentos sejam autoexplicativos, optou-se também por um breve comentário para contextualizar minimamente cada item.

Figura 1 - Variáveis da Condição de Atingido por Barragem

\begin{tabular}{|c|c|c|}
\hline \multicolumn{2}{|c|}{ VARIÁVEIS COLETIVAS } \\
\hline \multirow{2}{*}{ VARIÁVEIS } & DESDOBRAMENTOS & COMENTÁRIOS \\
\cline { 2 - 2 } & INDÍGENA & $\begin{array}{c}\text { Segundo esta variável, a discussão dar-se-á de } \\
\text { forma individualizada por unidade familiar, no } \\
\text { caso de colonos e caboclos, ou de forma } \\
\text { conjunta, no caso de indígenas e quilombolas. }\end{array}$ \\
\cline { 2 - 2 } ZONEAMENTO & COLONO & $\begin{array}{c}\text { O urbano tende a ser tratado de forma conjunta } \\
\text { (cidade), enquanto o rural tem sido tratado de } \\
\text { forma individualizada (propriedades) }\end{array}$ \\
\cline { 2 - 2 } & CABOCLO & $\begin{array}{c}\text { Comunidade em colapso é aquela localizada na } \\
\text { área de instalação da hidrelétrica, ocorrendo sua } \\
\text { desestruturação, enquanto a comunidade anfitriã é } \\
\text { aquela que recebe os remanejados da primeira. }\end{array}$ \\
\hline \multirow{2}{*}{ COMUNIDADE } & URBANO & \\
\cline { 2 - 3 } & EM COLAPSO & \\
\hline
\end{tabular}

DOI: https://doi.org/10.46699/rduno.v4i5.6050 | Edição Vol. 4, Núm. 5, 2021. 


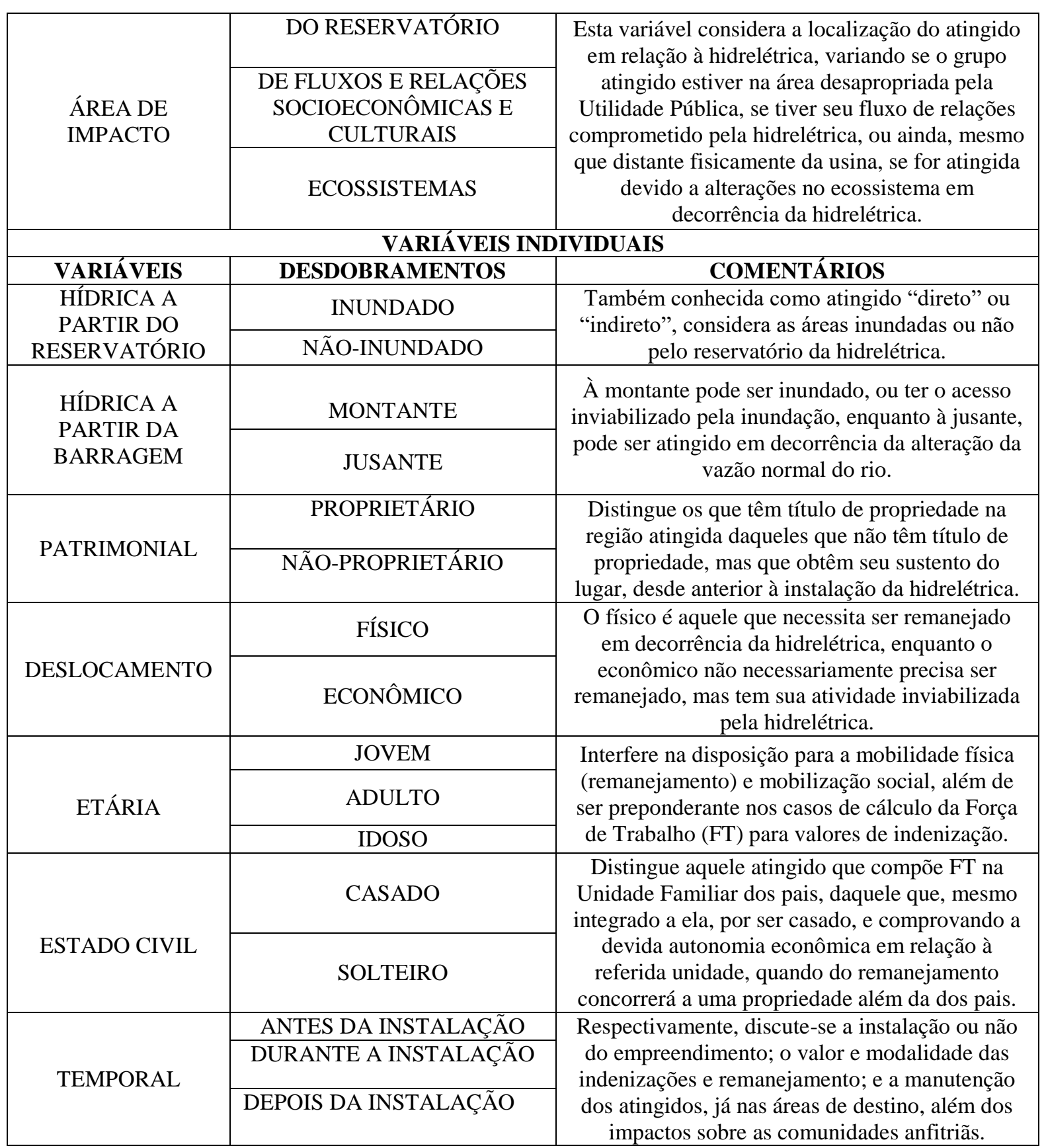

Fonte: Quadro elaborado pelo autor, principalmente com base nas informações de Vainer (2008).

Relacionadas as variáveis, seus desdobramentos e comentários iniciais, convém pôr à prova esses itens, para que seja demonstrada a sua validade e melhorado o entendimento (o que agora será feito seguindo a ordem do quadro).

No âmbito coletivo, a variável étnica, para além da diferença cultural, pesa no caso das hidrelétricas pelo fato de que, em se tratando de terras indígenas ou quilombolas, a discussão ou a indenização será tratada em relação ao grupo. No caso da UHE Foz do Chapecó, em que a Aldeia Condá (Kaingang) foi envolvida, as discussões desenvolveram-se no âmbito da aldeia, enquanto os DOI: https://doi.org/10.46699/rduno.v4i5.6050 | Edição Vol. 4, Núm. 5, 2021. 
colonos e caboclos da mesma região $0^{5}$ - proprietários de terras ou não - foram indenizados de forma individual. Sobre a variável do zoneamento rural ou urbano, o caso da UHE Itá é exemplar, pois enquanto os atingidos rurais foram tratados individualmente, o núcleo urbano foi relocado de forma conjunta, embora possa ocorrer da relocação de comunidades rurais também se dar de forma conjunta. A variável comunidade no caso da UHE Foz do Chapecó pode ser representada, respectivamente, pela comunidade do Saltinho do Uruguai, no município de Águas de Chapecó (SC), em colapso pela instalação do canteiro de obras, e pelo município de Mangueirinha (PR), comunidade anfitriã do Reassentamento Rural Coletivo (RRC), oriundo da referida hidrelétrica. Quanto à área de impacto, a mesma comunidade em colapso serve como exemplo de área inundada pelo reservatório, enquanto o distrito de Pratas, no município de São Carlos (SC), à jusante da barragem e calcado na atividade turística, tem seu fluxo econômico afetado pela alteração no fluxo do rio. Já em relação ao ecossistema, o aumento da cerração tem sido a principal queixa das comunidades próximas aos reservatórios, servindo como exemplo as queixas na vizinha UHE Monjolinho, no rio Passo Fundo, onde, segundo relatos, isso prejudicaria as atividades agrícolas.

No âmbito individual, que aqui se entende por unidade familiar ou, no limite, um indivíduo atingido, pode-se tomar as variáveis hídrica a partir do reservatório e patrimonial como básicas, assim como resultados de conquistas das mobilizações sociais ao longo do processo. As variáveis hídrica a partir da barragem e de deslocamento podem ser entendidas como sobreposições das variáveis coletivas explicadas anteriormente, exceto pelo fato de que, no sentido individual, elas podem condicionar apenas parte dos indivíduos de uma coletividade - daí, o tratamento ser individualizado. A variável etária tem se mostrado importante no sentido da predisposição para a migração e mobilização social, diferente entre jovens, adultos e idosos, além do fato que, considerando os cálculos de Força de Trabalho (FT), parâmetro acordado para o cálculo dos valores de indenizações, o peso da FT de cada pessoa varia de acordo com a idade. Quanto à variável sobre o estado civil, é preciso considerar que, em cada unidade familiar, o fato de os pais acolherem os filhos casados também reflete no cálculo dos valores das indenizações, o que, em muitos casos, pode ser interpretado pelos atingidos como uma possibilidade de reprodução do capital da família. A variável temporal talvez represente a principal variável no sentido da transitoriedade da condição de atingido, pois essa condição assume diferentes formas na medida em que as negociações e as obras

\footnotetext{
${ }^{5}$ A distinção dentro da variável étnica entre "colonos" e caboclos", embora englobe a mesma perspectiva de tratamento individualizado quando das negociações, é pertinente sobretudo nos estudos com maior densidade da descrição por envolver elementos históricos da ocupação do espaço, sobretudo, no sul do Brasil.
} 
das barragens avançam, uma vez que cada atingido poderá ter sua condição mais evidente em determinado momento do processo, seja pela notícia da construção, instalação do canteiro de obras, relocação em outra região, e assim por diante.

Resgatando as conceituações apresentadas a partir de estudos feitos na região, reforça-se a complexidade e mesmo a possibilidade de diferentes intepretações sobre um mesmo caso. Assim sendo, sem desconsiderar as diferentes conceituações sobre o que se entende como atingido por barragem, entender isso como uma condição não descarta o que foi apresentado nesses estudos. O que se pretende é apresentar elementos que podem orientar a análise de fatos complexos e partir da qual se constrói uma condição de atingido que é transitória em função do processo social. A próxima seção discute essa relação no sentido da construção de uma condição de atingido legítima, do ponto de vista moral, mas também legal, do ponto de vista técnico e jurídico.

\section{A CONSTRuÇÃo da CONDiÇÃo de Atingido Por BarRagem}

As variáveis apresentadas anteriormente compõem a condição de atingido por barragem em determinado caso. Não é demais reforçar que as variáveis relacionadas em determinado caso podem ser herdadas de casos anteriores, ou representarem novidades do caso em questão que ainda poderão compor casos futuros. Ocorre que essas variáveis não surgem naturalmente quando da instalação de um novo projeto hidrelétrico. É preciso ter em vista que a condição de atingido por barragem é uma construção que se dá a partir das relações de poder entre os diferentes agentes sociais envolvidos em cada caso.

Tomando por parâmetro o fato de que as relações de poder na instalação de uma hidrelétrica dão-se basicamente entre dois projetos políticos distintos ${ }^{6}$, um desenvolvimentista, que propõe a obra, e outro democrático-social, que questiona aspectos da mesma obra, é possível dizer que as variáveis elencadas para cada caso acabam por compor o quadro de duas formas: consensual ou litigiosa, assim, para explicar melhor essas formas, volta-se ao exemplo da UHE Foz do Chapecó, na bacia do rio Uruguai.

Na UHE Foz do Chapecó, considerando sua história a partir da emissão da LI (quando se iniciam, de fato, as obras para a instalação da hidrelétrica), formou-se um Fórum de Negociação

\footnotetext{
${ }^{6}$ A ideia de projeto político neste trabalho baseia-se no seguinte referencial: DAGNINO, E. Confluência perversa, deslocamentos de sentido, crise discursiva. In: GRIMSON, A. La cultura en las crisis latinoamericanas. Buenos Aires: Clacso, 2004. DAGNINO, E.; OLVERA, A. J.; PANFICHI, A. (Orgs.). Para uma outra leitura da disputa pela construção democrática na América Latina. In: A disputa pela construção democrática na América Latina. São Paulo; Campinas: Paz e Terra: UNICAMP, 2006.
} 
prevendo a participação da Foz do Chapecó Energia (FCE) - consórcio responsável pela obra -, dos Comitês Municipais de cada um dos doze municípios atingidos, das Associações constituídas para representação dos atingidos, além do Movimento dos Atingidos por Barragens (MAB), que se recusou a compor o Fórum por não concordar com sua forma e conteúdo. Independente da visão que se tenha dessa instância, o certo é que as disputas e as decisões derivadas dela tiveram seus rumos definidos a partir de relações de poder entre os envolvidos, considerando sua capacidade de argumentação, de barganha e até de pressão sobre os outros membros envolvidos. Desse Fórum, originou-se um "Termo de Acordo" entre os participantes, no qual se estabeleceram as diretrizes gerais para a indenização dos atingidos. Através desse documento, ficou acordado quem seria considerado um atingido pela UHE Foz do Chapecó, logo, com direito à indenização segundo os termos do mesmo acordo. Esse Acordo traduz o consenso ${ }^{7}$ sobre as variáveis apresentadas por ambas as partes, que acabaram compondo um quadro geral em cujo caso se vislumbra a condição de atingido.

O consenso, nesse caso, como na maioria das instalações de hidrelétricas, foi mostrando sua limitação à medida que as obras avançavam. Fora do consenso, para além da pressão social de ambas as partes, é correto afirmar que o Direito é o campo onde se dá a definição da condição de atingido por barragem. Neste sentido, dois pontos podem exemplificar a recorrência ao Direito para discussão da condição de atingido no caso da UHE Foz do Chapecó: no âmbito coletivo, uma Ação Civil Pública, movida pelo Ministério Público Federal em favor da Comunidade Indígena Aldeia Condá, pedia providências a partir da condição daquela comunidade; no âmbito individual, 61 processos judiciais envolvendo a FCE e famílias atingidas representam o litígio entre as partes em relação à condição de atingido de cada uma dessas famílias.

Ao optar pela discussão através do viés jurídico, as partes são submetidas às regras formais e dispõem-se a traduzir suas aspirações do mundo social em termos técnicos inerentes a esse campo. Embora o processo judicial não destoe definitivamente da realidade do mundo social - disso depende seu prestígio -, podendo sofrer influências de outros campos, muito do resultado da disputa vai depender da habilidade técnica dos profissionais representantes de cada parte (BOURDIEU, 2009b). Tomando como parâmetro a discussão de uma variável da condição de atingido, partindo do princípio de que esta tenha fundamento lógico, para ter efeito, então, dependerá da homologação do

\footnotetext{
${ }^{7}$ Sobre essa ideia de "consenso" na instalação de hidrelétricas, ver: VOLKWEIS FILHO, Pedro Luiz. A legitimação da harmonia coercitiva nos processos de licenciamento ambiental: o caso da UHE Barra Grande. (Dissertação de Mestrando em Direito). Universidade Comunitária da Região de Chapecó, 2017.
} 
Direito, independentemente de a sua idealização ter sido consensual ou litigiosa. Considerando uma variável que tenha sido homologada em determinado caso, se ela for condizente em outros casos poderá servir como parâmetro para decisões futuras, o que, feito de forma contínua, acaba se tornando uma "codificação", ou seja, um padrão para esse tipo de discussão. Podem-se citar como exemplos as indenizações aos não-proprietários, que, nas primeiras obras, eram excluídos do processo indenizatório, ao passo em que, atualmente, devido a um direito adquirido durante a instalação de uma hidrelétrica, tornou-se parâmetro para as seguintes, mesmo que necessite de atualização em cada caso.

Portanto, é preciso deixar claro que a condição de atingido não é conferida automaticamente às pessoas que habitam o local da instalação de uma hidrelétrica. Ao contrário, essa condição vai sendo construída ao longo de um processo social amplo que envolve todas as hidrelétricas instaladas e que se reconfigura em cada novo projeto. Essa construção incide sobre cada variável de forma individualizada ou conjunta, tendo em vista que cada atingido tem sua condição fundada em uma variável específica, ou na sobreposição delas. Consensual ou litigiosa, a condição de atingido por barragem é o resultado de relações sociais que discutem variáveis legítimas que precisam ser também legais do ponto de vista jurídico.

O que foi apresentado até aqui sobre a construção da condição de atingido refere-se ao aspecto de reivindicação de direitos indenizatórios decorrentes da instalação da hidrelétrica. Outro aspecto dessa construção precisa ser mencionado: aquele no qual a condição de atingido aproximase da ideia de identidade social. Essa dimensão da condição de atingido não está necessariamente relacionada com as variáveis propostas na seção anterior. O que acontece nessa dimensão, basicamente, é que os projetos políticos em disputa na instalação da hidrelétrica - o desenvolvimentista e o democrático-participativo -, a partir da ação dos mediadores ${ }^{8}$, vão se relacionar com os atingidos pela hidrelétrica em questão da forma a tentar influenciar suas decisões em favor do projeto que representam, ensejando que o empreendedor pretenda um perfil de negociante aos atingidos, enquanto o Movimento dos Atingidos por Barragens (MAB) pretende um perfil militante para esses atingidos.

$\mathrm{Na}$ linha do que apresentou Guedes (2006), pode-se dizer que o MAB, a partir de ações pedagógicas, discursivas e ideológicas, atua no sentido da formação de quadros de militância, que

\footnotetext{
${ }^{8}$ A questão da mediação, sobretudo no que se refere aos movimentos sociais do campo, dentre os quais o MAB, está mais bem analisada noutro trabalho. Ver: ROCHA, H.J.. Elementos para pensar a mediação nos movimentos sociais no campo. In: MACHADO, I.A.P.; BACCIN, D.J.; TEDESCO, J. C.. (Orgs.). Mundo rural, regiões e fronteiras no processo de (re)apropriação territorial e agrária. Passo Fundo: EDIUPF, 2019, p. 201-229.
}

DOI: https://doi.org/10.46699/rduno.v4i5.6050 | Edição Vol. 4, Núm. 5, 2021. 
podem ser compostos por aqueles que estão na condição de atingido, mas também por outros que não estão na condição de atingido, de acordo com as variáveis aqui apresentadas, ainda que necessariamente identifiquem-se com a causa e militem em favor do movimento social. Neste ponto, a diferença entre condição e identidade de atingido por barragem é passível de apontamento, uma vez que, enquanto a primeira refere-se ao "conjunto das populações cujas condições de vida são negativamente afetadas pela construção da barragem", o segundo é "aquele que é formado pela atuação do MAB, com o objetivo de sua constituição enquanto quadro ou militante" (GUEDES, 2006, p. 104, grifo nosso).

A partir da pesquisa empírica durante o processo de instalação da UHE Foz do Chapecó, percebem-se alguns aspectos que apontam para a atuação da FCE no sentido de incentivar a negociação das indenizações por parte dos atingidos, ao invés da discussão pelo viés político. A organização do Fórum de Negociação, as parcerias com as Prefeituras Municipais e o apoio a associações como a Associação Mista dos Municípios Atingidos pela Barragem da Foz do Chapecó (AMISTA) - o que legalmente é considerado como obrigação do empreendedor no sentido de democratizar a discussão - têm priorizado a discussão voltada para os valores a serem recebidos por aqueles reconhecidos como atingidos. Além do fato de que as decisões referentes às indenizações, na maioria das vezes, são resultado desse Fórum, é possível especular que, a partir do momento em que o empreendedor negocia individualmente com cada atingido - e sendo ele quem paga a indenização -, possa ocorrer de ele mesmo regular o ritmo de cada processo de acordo com o perfil do atingido a ser indenizado; ou seja, pode acontecer que algumas indenizações sejam feitas de forma mais rápida e flexível do que outras. Isso poderá repercutir entre os atingidos no sentido de apontar qual o melhor caminho para tratar de seus interesses ${ }^{9}$.

Em suma, é preciso entender que a condição de atingido é uma construção a partir de relações de poder entre os diferentes agentes sociais, no tocante a homologar juridicamente - de forma amigável ou litigiosa - as variáveis que concedem às populações seus direitos decorrentes da instalação da hidrelétrica. Já a identidade de atingido também precisa ser construída, porém ela não segue o mesmo caminho e tem um sentido que pode ir além da reivindicação de direitos por parte das comunidades, manifestando-se na militância política a partir da hidrelétrica, mas relacionada a questões mais amplas do mundo social.

\footnotetext{
${ }^{9}$ Essa discussão está aprofundada no trabalho: ROCHA, Humberto José da. O controle do espaço-tempo nos processos de instalação de hidrelétricas. Tempo Social, 26(1), 2014, pp. 259-280.
}

DOI: https://doi.org/10.46699/rduno.v4i5.6050 | Edição Vol. 4, Núm. 5, 2021. 


\section{A Transitoriedade da CONDiÇão de Atingido POR BarRagem}

A afirmação da transitoriedade da condição de atingido pretende assinalar que essa condição muda de acordo com o andamento do processo de instalação de uma hidrelétrica. Não significa dizer que, automaticamente, alguém passa a ser atingido a partir dos primeiros movimentos de instalação da obra e deixa de ser quando esta é concluída. É preciso ter em vista que, diante da complexidade de variáveis que podem compor a condição de atingido, não se podem homogeneizar tampouco estabelecer o começo e o fim dessa condição, mas sua transitoriedade.

Como já foi expresso, a instalação de hidrelétricas precisa ser entendida enquanto processo social, que, no Brasil, já possui mais de um século transcorrido. Como a condição de atingido é mais bem esclarecida se tomada em cada caso distintamente, optou-se por apresentar a discussão em três momentos da instalação de uma hidrelétrica: antes da LI, durante a LI, e depois da LI. Isso sem que esses três momentos sejam tomados como cortes instantâneos no processo de instalação, mas como uma forma de mostrar de que maneira o andamento das obras e negociações para a instalação da usina, em diferentes momentos, podem influenciar e ser influenciados pelas variáveis apresentadas anteriormente, isto é, pela própria condição de atingido.

\section{Antes da Licença de Instalação (LI)}

Esse período da instalação da hidrelétrica, que compreende desde a notícia da instalação da obra na região até a emissão da LI, é marcado pela discussão acerca das vantagens e desvantagens da obra para a região e o país, o que acontece principalmente através da ação de mediadores no sentido de promover a identificação dos atingidos com seus respectivos projetos políticos.

Diante da complexidade da sociedade atual, é importante a ideia dos "quase-grupos", ao referir-se a indivíduos ou grupos sem uma estrutura organizacional definida, mas que, pela situação em que se encontram em determinado momento, podem ou não vir a formar um grupo, mesmo que esse sobreviva apenas enquanto a situação exigir. Além de apresentar a importância desse conceito, é preciso esclarecer quais os pontos e quais as circunstâncias em que os quase-grupos podem emergir e como podem ser influenciados nessa perspectiva espaço-temporal (MAYER, 1987, p. 151-152). Seguindo a proposta de Mayer, a instalação de uma hidrelétrica pode ser tomada como uma circunstância em que os quase-grupos poderão vir a formar grupos de acordo com o lugar onde a obra é proposta (espaço) e o seu andamento (tempo). Na mesma linha, mas, especificamente sobre hidrelétricas, Almeida (1994) afirma que "de acordo com as lutas localizadas e imediatas 
constituem-se, pois, unidades de mobilização de cuja coesão social não se pode duvidar tanto pela uniformidade de suas práticas, quanto pela força com que se colocam nos enfrentamentos diretos", sendo que esses grupos sociais podem receber denominações como "comissões", "conselhos", “associações” ou “comunidades" (ALMEIDA, 1994, p. 523, grifo nosso).

Retomando a discussão a partir de dois projetos políticos em disputa, entende-se que a configuração das unidades de mobilização, em determinado caso, depende muito da ação dos mediadores, que estabelecem uma relação entre os projetos amplos e os interesses locais (WOLF, 2003). No caso das hidrelétricas, pode-se perceber a configuração das unidades de mobilização de acordo com a ação dos mediadores, sejam desenvolvimentistas ou democrático-participativos, o que não significa dizer que os atingidos estejam à mercê da influência dos mediadores, mas que, de acordo com a sua condição, relacionada com a ação desses mediadores, poderão compor diferentes grupos sociais, buscando defender seu ponto de vista, fortalecendo o projeto político a que se relacionam.

No caso da UHE Foz do Chapecó, no período considerado anterior à emissão da LI, a ação do MAB deu-se a partir de militantes que já haviam atuado na região em decorrência da instalação das UHEs Iraí e Itapiranga, na década de 1980 - ambas suspensas, em boa parte devido à ação do MAB -, e pela formação de lideranças de base, no decorrer da discussão sobre a UHE Foz do Chapecó ainda nos primeiros anos de 2000. Percebe-se, na composição dessa unidade de mobilização, haver atingidos em diferentes condições (proprietários e não-proprietários, à montante e à jusante) que se manifestavam pautados no sistemático questionamento das vantagens da obra para a região, propondo, no limite, a sua suspensão. Do outro lado, sob a mediação principalmente dos governos municipais, a obra foi defendida baseada no desenvolvimento que poderia proporcionar à região. Essa unidade de mobilização também reuniu atingidos em diferentes condições - nas mesmas daqueles representados pelo MAB -, mas, sobretudo, da população urbana ou mais afastada do local do canteiro de obras. Essa unidade de mobilização consistiu principalmente nos Comitês Municipais, que discutiam com os empreendedores a instalação da obra, conforme previa a legislação em vigor.

Outro caso digno de registro diz respeito aos indígenas na UHE Foz do Chapecó. Se forem tomados casos como a UHE Belo Monte (Pará), ou mesmo a UHE Monjolinho (vizinha da UHE Foz do Chapecó no RS), verifica-se a contrariedade dos indígenas em relação a essas obras e uma tendência à aliança com o MAB. Na UHE Foz do Chapecó, embora não fossem atingidos, os indígenas da Aldeia Condá foram envolvidos na questão através de um anexo ao edital de construção 
da hidrelétrica que, em linhas gerais, condicionava ao vencedor do leilão a compra de uma área de terra a ser destinada à criação de uma Reserva Indígena. A partir disso, a condição da Aldeia passou a estar diretamente ligada à concretização do projeto e, logo, os indígenas posicionaram-se quanto a sua condição, o que acabou alterando significativamente as relações de poder naquele caso. ${ }^{10}$

Dessa forma, pode-se perceber que, antes da LI, a condição de atingido dá-se principalmente no âmbito coletivo de forma a discutir os prós e os contras da instalação da obra na região. Esse é o momento em que é mais forte a ação dos mediadores de projetos antagônicos no sentido de identificar os atingidos aos seus programas. No caso em questão, com a Licença Prévia (LP) concedida em 13 de dezembro de 2002 (com validade de dois anos), a FCE teve a LI concedida em 21 de setembro de 2004 (também com validade de dois anos) e começou a instalação do canteiro de obras, o que foi interrompido, em boa parte, pela ação de militantes do MAB que chegaram a ficar 19 meses acampados no canteiro de obras. Pela interrupção no processo, a LI foi renovada em 5 de dezembro de 2006 (esta com validade de quatro anos) e a obra seguiu o cronograma do empreendedor, deslocando a discussão sobre a condição de atingido e seus reflexos para um outro viés.

\section{Durante a Licença de Instalação}

A partir da LI, com o início da instalação do canteiro de obras, as discussões que até então estavam voltadas para o aspecto geral do projeto e variáveis coletivas da condição de atingido vão, gradativamente, sendo permeadas por discussões mais pontuais, e as variáveis individuais ganham destaque na medida em que a obra insere-se, de fato, na região em questão. Pode-se dizer que esse é o período de maior efervescência da discussão sobre a condição de atingido por barragem, por ser o momento em que se define o destino dos atingidos.

Enquanto na fase anterior da discussão, antes da LI, os projetos políticos tinham preponderância na condução das discussões, com a definição de que a hidrelétrica será instalada e o início das obras, percebendo-se uma mudança na pauta das discussões. Schutz (1979, p. 76) explica que "na vida diária é só parcialmente - e ousamos dizer, excepcionalmente - que o homem se interessa pela clareza de seu conhecimento, isto é, por uma visão mais profunda das relações entre

\footnotetext{
10 Trata-se do Anexo 11 ao Edital de Leilão n ${ }^{\circ}$ 002/2001-ANEEL. Já sobre os indígenas e a UHE Foz do Chapecó, ver: FERNANDES, Ricardo Cid. Terra, tradição e identidade: os Kaingang da Aldeia Condá no contexto da UHE Foz do Chapecó. In: SANTOS, Sílvio Coelho dos; NACKE, Anelise. (Orgs.). Hidrelétricas e povos indígenas. $1^{\mathrm{a}}$ ed. Florianópolis: Letras Contemporâneas, 2003, p. 158-175.
} 
os elementos desse mundo e os princípios gerais que as regulam”; ele vai além, quando afirma que "tudo o que [o homem] quer é informação sobre possibilidades, e visão das chances e riscos que a situação à mão acarreta com relação ao resultado de suas ações”. Essa perspectiva fenomenológica ilumina o entendimento sobre as posturas dos atingidos ante a instalação da hidrelétrica. Sob essa perspectiva, eles agirão de acordo com a sua condição de atingido, a qual, quando das negociações, tenderão a privilegiar o que entenderem, naquelas situações e segundo as suas condições, como sendo o melhor para a unidade familiar.

Sem ignorar a influência que os mediadores dos projetos políticos podem exercer sobre as decisões de cada atingido, nem tomando o mesmo atingido como um ser apolítico, é importante retomar as palavras de Schutz (1979, p. 233), quando o autor afirma que "em qualquer interação social, uma porção do sistema de relevâncias intrínsecas de cada parceiro permanece não compartilhada pelo outro". Na medida em que os dois parceiros têm relevâncias distintas, a maior ou menor afinidade entre as relevâncias daquele que propõe algo (MAB ou FCE) em relação àquele que é objeto da proposta (os atingidos) tornará as ideias dos primeiros mais ou menos atrativas aos olhos dos últimos. Em outras palavras, nessa fase da instalação da hidrelétrica, as diferentes condições entre os atingidos, de acordo com as variáveis que as orientam, contribuem significativamente para que cada um assuma uma postura condizente com sua condição, tendendo relegá-la para um plano secundário à mediação dos projetos distintos que preponderaram na fase anterior do processo.

No caso da UHE Foz do Chapecó, os projetos políticos apresentaram-se principalmente por meio de dois mediadores: o MAB, personagem histórico na questão das barragens, que aparece com a proposta de Reassentamento Rural Coletivo (RRC); e a AMISTA, que propunha a negociação através da Indenização em Dinheiro e da Carta de Crédito. Além dessas vias de negociação, é preciso ter em vista que os governos municipais, os Sindicatos de Trabalhadores Rurais (STR), Sindicatos Patronais dos Trabalhadores Rurais (SPTR) e as Igrejas (Católica e Luterana) também exercem importante papel de mediação em relação aos atingidos, além da possibilidade de eles tratarem seu caso diretamente com o empreendedor.

No caso exemplificado, a quase totalidade dos atingidos está no meio rural, o que torna importantes duas considerações. Primeiro, a afirmação de Scherer-Warren et al. (1990, p. 31-32), quando explicam que, diante da incerteza, os colonos da bacia do rio Uruguai tendem a "repensar seu modo de vida, reatualizando, assim, sua identidade”. Neste sentido, são enfatizados aspectos como "trabalhadores livres", "não ter patrão", "ser dono do próprio tempo", "produção autônoma 
da própria subsistência", além dos "fortes laços sociais que os unem", e sem esquecer, ao final, da "consciência de que seu trabalho é árduo e que se desenvolve de 'sol a sol"”. Assim sendo, tendem a fazer uma idealização do passado e do presente diante da incerteza do futuro, de modo que essa idealização norteia sua conduta na negociação. Segundo, é preciso ter em mente que o agricultor (neste caso, colono ou caboclo) tem sua vida pautada no que Garcia Jr. (1989) chama de "cálculo", que o agricultor faz num sentido amplo, de acordo com o ciclo agrícola, quando precisa avaliar se esse será bom ou mau, para definir coisas como o tamanho da área a ser destinada à produção para a venda e subsistência, quanto de semente e adubo vai comprar e o que vai plantar, de acordo com os preços do mercado e a variação climática. Além desse cálculo maior, outros serão constantemente necessários nas suas atividades quando definem a execução de tarefas diárias, semanais ou mensais, como a distribuição do trabalho dentro da unidade familiar, a recorrência ou não à ajuda, a troca de dias ou trabalho assalariado e o melhor momento para o plantio ou colheita de acordo com o clima e os preços naquele momento.

As duas considerações feitas anteriormente servem para mostrar que, no momento das negociações referentes à indenização, a relevância primeira que orientará a opção dos atingidos, considerando o meio rural, é a sua identidade camponesa, fundada principalmente na unidade familiar, que vai ser seguida pelo cálculo que esses camponeses farão a partir do que entendam como as melhores possibilidades de reprodução dessa identidade ${ }^{11}$. Isso ainda poderá distinguir-se de acordo com as variáveis que condicionam cada atingido. A pesquisa empírica na UHE Foz do Chapecó demonstrou que, dentre os que optaram pelo RRC, a maioria era de não-proprietários, enquanto as Cartas de Crédito foram opção da maioria dos pequenos proprietários (até 15 ha) e a indenização em dinheiro foi a opção daqueles que possuíam uma propriedade maior e mais bem estruturada.

A partir do exposto, pretendeu-se mostrar a importância da condição de atingido para a tomada de decisão individual, já que, considerando a temporalidade, nesse período do processo, tende a prevalecer entre os atingidos uma postura de negociadores, já que é relevante a discussão de uma opção dentre as possibilidades de indenização e remanejamento. Mas esse perfil negociante, embora preponderante, não anula o perfil militante. Pode-se dizer que as conquistas obtidas pelo MAB, em casos como a UHE Itá, deram-se, em grande parte, pela quantidade de atingidos que o movimento representava, o que garantia, de certa forma, seu poder de pressão e barganha. Isso

\footnotetext{
11 Ver: SHANIN, Teodor. A definição de camponês: conceituações e desconceituações: o velho e o novo em uma discussão marxista. Estudos CEBRAP, São Paulo, nº 26, 1976, p. 42-80.
}

DOI: https://doi.org/10.46699/rduno.v4i5.6050 | Edição Vol. 4, Núm. 5, 2021. 
reforça a ideia de que as variáveis que podem conferir diferentes condições de atingido num determinado caso, associadas à multiplicidade de mediadores e alternativas de negociação, aumentam a complexidade da discussão acerca da instalação das hidrelétricas, o que precisa ser tratado pelo estudo de caso.

\section{Depois da Licença de Instalação}

Concluído o processo de instalação da hidrelétrica, o próximo passo no cronograma da obra é a Licença de Operação (LO). A condição de atingido por barragem não é necessariamente superada com o início da operação da usina e a indenização ou remanejamento da população. No aspecto coletivo, as variáveis de comunidade e área de impacto estarão em evidência, enquanto no aspecto individual, a condição pode mudar de acordo com variáveis decorrentes das duas fases anteriores, quando se diferencia o atingido negociante do militante e, de acordo, respectivamente, com a forma de negociação e com as relações de poder, sobretudo, as mobilizações sociais.

No aspecto coletivo, a variável a partir da área de impacto vai apontar a condição de atingido de acordo com a interferência da reconfiguração territorial e social na área. Conforme ocorrido recentemente, um taxista do município gaúcho de Arroio do Tigre teve sua condição de atingido reconhecida judicialmente (em primeira instância), em decorrência da instalação da UHE Dona Francisca, no rio Jacuí, que teria comprometido sua atividade devido ao remanejamento de sua clientela. Ainda no Rio Grande do Sul, viticultores da Cooperativa Vinícola Aurora Ltda. discutem sua condição em relação ao Complexo Energético do Rio das Antas, formado pelas UHEs Castro Alves, Monte Claro e 14 de Julho, questionando os efeitos da alteração climática sobre a vitivinicultura regional.

Sobre os desdobramentos da variável comunidade, o caso da UHE Foz do Chapecó é exemplar. O município paranaense de Mangueirinha tem recebido reassentamentos não apenas dessa hidrelétrica, mas também das UHEs Salto Segredo e Itá. Isto posto, é preciso verificar qual a situação das famílias reassentadas em relação à estrutura do município anfitrião, pois, neste sentido, tanto as famílias reassentadas quanto a população local podem ser consideradas atingidas, já que o aumento significativo da população sem a devida adequação dos serviços do referido município pode refletir na qualidade de vida (como, por exemplo, educação, segurança, saúde e transporte públicos). Manifestações recorrentes de lideranças de reassentamentos, tanto no município de Mangueirinha como no município vizinho de Palmas, apontam para esse problema. 
Já no aspecto individual, de acordo com o desfecho das negociações de indenização, atingido pode ter sua condição alterada depois da LI. É difícil afirmar, com certeza, qual a forma de indenização é a melhor. Isso vai depender da condição específica de cada atingido. O Reassentamento Rural Coletivo (RRC), por reunir um número maior de atingidos, pode exercer maior pressão sobre as prefeituras anfitriãs e o próprio empreendedor, no sentido de melhorias da sua condição. Os indenizados por Carta de Crédito ou Indenização em Dinheiro têm, na liberdade da escolha da região onde queiram instalar-se, configura-se como um aspecto importante no momento da negociação, mas que pode dificultar eventuais reclamações sobre a condição deles com o passar do tempo em função da desmobilização social.

É importante retomar o que foi expresso sobre a construção da condição de atingido negociante ou militante, a partir da ação dos mediadores e das variáveis as quais estão sujeitos os atingidos. Mesmo com o final da instalação de uma hidrelétrica e a devida relocação dos atingidos, pode ocorrer dele continuar apoiando o MAB nas mobilizações em outras hidrelétricas ou, tendo a sua situação resolvida, afastar-se, com o passar do tempo, dessa condição. Isso pode ser exemplificado pelo caso da UHE Foz do Chapecó, pois tem, no principal líder local do MAB, um exemplo de atingido em potencial pela UHE Itapiranga, que teve sua instalação interrompida, em boa parte, por ações de militância da qual essa liderança participou, ao passo que atingidos da UHE Foz do Chapecó já compõem o quadro do MAB e, possivelmente, militarão em outras hidrelétricas, inclusive na próxima - que seria aquela de Itapiranga -, novamente em discussão na região. Sobre a participação de atingidos de hidrelétricas anteriores na militância contra a instalação da UHE Foz do Chapecó, tal liderança citada afirma ser quase nula, a não ser naqueles casos em que a ação pedagógica do MAB tornou o atingido negociante em militante, passando a ser incluído nos quadros desse movimento social.

Além do que foi expresso nesta sessão, é preciso chamar a atenção para dois aspectos importantes relacionados à fase posterior à instalação das hidrelétricas. Primeiro, o fato de que muitos atingidos que reivindicam sua condição nesse momento não tinham consciência dela durante a instalação da obra, chegando, muitas vezes, a aprová-la. A atividade de taxista, por exemplo (sem se referir ao caso mencionado anteriormente neste trabalho), pode ser contraposta pela sua condição durante a instalação. Tanto que uma visita à região do canteiro de obras da UHE Foz do Chapecó pode fundamentar essa hipótese em decorrência da fila de táxis que se formava no local, podendose especular quais daqueles estariam na condição de atingido quando o fluxo de pessoas diminuir na região. Finalmente, é preciso questionar que a noção de desenvolvimento regional, quando se trata 
do período de operação das hidrelétricas, é observado apenas a partir do retorno financeiro ao município como um todo, ao passo que a questão ambiental, além da condição daqueles que foram expropriados, nem sempre é considerada.

\section{CONSIDERAÇÕES FINAIS}

A condição de atingido por barragem advém de uma construção a partir da relação entre diferentes agentes sociais na questão hidrelétrica, que reúne desde grupos de empresas multinacionais, assim como nacionais (como o Estado) até locais (como ribeirinhos que raramente deixaram a barranca do rio ao longo de suas vidas). Essa relação tem sido marcada por negociações e pressões, mas, de uma maneira ou de outra, acabam homologadas judicialmente, de forma que, a partir de sua aplicação repetida, a cada novo caso, pode significar alterações no sentido de um processo social amplo que, como se sabe, no Brasil já ultrapassa um século.

Embora precise ser tratada segundo um processo social longo, em cada nova hidrelétrica, as variáveis da condição de atingido sofrem desdobramentos de acordo com a especificidade do caso em questão. Além dessa especificidade, a transitoriedade das variáveis, de acordo com os diferentes momentos do processo de instalação de uma hidrelétrica - aqui destacados como antes, durante e depois da LI -, conferem à condição de atingido uma flexibilidade que pode ter seu início marcado pela notícia da obra na região, porém, que não pode ter seu final decretado pelo término das obras nem pelo reassentamento ou indenização dos respectivos atingidos.

A processualidade, transitoriedade e especificidade conferem à condição de atingido por barragem uma natureza relacional que se define enquanto uma construção, individual ou coletiva, a partir da situação de cada atingido, e que, diante da ação de mediadores de diferentes projetos políticos, acaba se posicionando em relação à obra de forma a resolver a sua situação pelo caminho que acredita ser o mais indicado no seu caso. Contudo, ao fazer isso, contribui para a configuração dos grupos sociais que compõem a arena de discussões sobre a hidreletricidade.

Ao reafirmar a importância das qualificações conceituais dos atingidos por barragens tanto pelas organizações quanto nos diferentes trabalhos acadêmicos, procurou-se, ao longo deste trabalho, assinalar a natureza complexa da questão hidrelétrica. Desse modo, não obstante a validade dos aspectos positivos e negativos destacados em trabalhos referenciados no início deste artigo, é importante considerar o atingido por barragem segundo uma construção que reúne aspectos ideológicos, pragmáticos e utilitários que têm uma natureza temporalmente transitória em função 
das relações de poder que acontecem de forma específica em cada hidrelétrica conformando um processo social amplo.

Finalmente, para compreender a condição de atingido em sua complexidade, é preciso considerar cada hidrelétrica em suas nuances e em relação com o processo social mais amplo. Ante a dificuldade de estabelecer um conceito completo e definitivo de atingido por barragem, o que precisa ser assegurado é a garantia da qualidade do processo decisório de instalação dessas obras de grande escala observando atributos legais e legítimos para que a geração de energia não se torne um benefício para a sociedade geral à custa de sacrifícios de populações locais.

\section{REFERÊNCIAS}

ALMEIDA, Alfredo Wagner Berno de. Universalização e localismo: movimentos sociais e crise dos padrões tradicionais de relação política na Amazônia. In: D'INCAO, Maria Angela; SILVEIRA, Isolda Maciel de. Amazônia e a crise da modernização. Belém: Museu Paraense Emílio Goeldi, 1994, p. 521-537.

ARENDT, Hannah. A condição humana. 10. ed. Rio de Janeiro: Forense Universitária, 2005.

BARON, Sadi. UHE Foz do Chapecó: estratégias, conflitos e o desenvolvimento regional. Dissertação (Mestrado em Políticas Sociais e Dinâmicas Regionais) - Programa de Pós-Graduação em Políticas Sociais e Dinâmicas Sociais, Universidade Comunitária da Região de Chapecó, Chapecó, 2012.

BIROU, Alain. Dicionário das Ciências Sociais. Lisboa: Publicações Dom Quixote, 1973.

BOAMAR, Paulo Fernando de Azambuja. A implantação de empreendimentos hidroelétricos: o caso da UHE de Machadinho. Dissertação (Mestrado em Engenharia de Produção) - Programa de Pós-Graduação em Engenharia de Produção, Universidade Federal de Santa Catarina, Florianópolis, 2003.

BORGES, Douglas Anderson. A construção do conceito de atingido por empreendimentos hidrelétricos. Dissertação (Mestrado em Direito) - Programa de Pós-Graduação em Direito, Universidade Comunitária da Região de Chapecó, Chapecó, 2020.

BORGES, Marcia Leite. Barragens no Sul do Brasil: análise de políticas compensatórias e da qualidade de vida. Dissertação (Mestrado em Ciência Política) - Programa de Pós-Graduação em Ciência Política, Instituto de Filosofia, Sociologia e Política, Universidade Federal de Pelotas, Pelotas, 2015.

BOURDIEU, Pierre. Introdução a uma sociologia reflexiva. In: BOURDIEU, Pierre. O poder simbólico. Rio de Janeiro: Bertrand Brasil, 2009a. pp. 17-58. 
BOURDIEU, Pierre. A força do direito: elementos para uma sociologia do campo jurídico. In: BOURDIEU, Pierre. O poder simbólico. Rio de Janeiro: Bertrand Brasil, 2009b. pp. 209-254.

ELIAS, Norbert; SCOTSON, John L. Os estabelecidos e os outsiders: sociologia das relações de poder a partir de uma pequena comunidade. Rio de Janeiro: Zahar, 2000.

ELIAS, Norbert. Escritos \& ensaios 1: Estado, processo e opinião pública. Rio de Janeiro: Jorge Zahar Ed., 2006.

GARCIA JUNIOR, Afrânio Raul. O sul: caminho do roçado: estratégias de reprodução camponesa e transformação social. São Paulo; Brasília, DF: Marco Zero: Ed. Universidade de Brasília: MCTCNPq, 1989.

GUEDES, André Dumans. Projeto identitário, discurso e pedagogia na constituição de um sujeito coletivo: o caso dos atingidos por barragens. Dissertação (Mestrado em Planejamento Urbano e Regional), Programa de Pós-Graduação em Planejamento Urbano e Regional, Universidade Federal do Rio de Janeiro, Rio de Janeiro, 2006.

LÉVI-STRAUSS, Claude. Introdução à obra de Marcel Mauss. In: MAUSS, Marcel. Sociologia e Antropologia. São Paulo: Cosac Naify, 2003, pp. 11-46.

MARTINS, José de Souza. Fronteira: a degradação do outro nos confins do humano. São Paulo: Hucitec, 1997.

MAUSS, Marcel. Ensaio sobre a dádiva: forma e razão da troca nas sociedades arcaicas. In: MAUSS, Marcel. Sociologia e Antropologia. São Paulo: Cosac Naify, 2003, pp. 183-314.

MAYER, Adrian C. A importância dos "quase-grupos" no estudo das sociedades complexas. In: FELDMAN-BIANCO, Bela. (Org.). Antropologia das sociedades contemporâneas. São Paulo: Global, 1987, pp. 127-158.

MORETTO, Evandro Mateus; GOMES, Carina Sernaglia; ROQUETTI, Daniel Rondinelli; JORDÃO, Carolina de Oliveira. Histórico, tendências e perspectivas no planejamento espacial de usinas hidrelétricas brasileiras: a antiga e atual fronteira Amazônica. Ambiente \& Sociedade, 15(3), 2012, pp. 141-164.

NÓBREGA. Renata. S. Os atingidos por barragem: refugiados de um guerra desconhecida. REMHU - Revista Interdisciplinar da Mobilidade Humana, v. 19, n. 36, Jan-Jun, 2011, pp. 125143.

OLIVEIRA, Nathalia Capellini Carvalho de. A grande aceleração e a construção de barragens hidrelétricas no Brasil. Varia Historia, 34(65), 2018, pp. 315-346.

PASE, Hemerson Luiz; LINHARES, Bianca; MATOS, Isis O. B.. As políticas compensatórias e a satisfação dos atingidos por hidrelétricas. In: Anais do IX Encontro da Associação Brasileira de Ciência Política: 1964-2014 - autoritarismo, democracia e direitos humanos, Brasília: 2014. 
RENK, Arlene; WINCKLER, Silvana. Os direitos humanos das vítimas de grandes empreendimentos: ampliando a percepção sobre impactos socioambientais decorrentes da UHE Foz do Chapecó. 30ª Reunião Brasileira de Antropologia, João Pessoa, 2016.

RIBEIRO, Gustavo Lins. Empresas transnacionais: um grande projeto por dentro. São Paulo: Marco Zero: ANPOCS, 1991.

SCHERER-WARREN, Ilse; REIS, Maria José; BLOEMER, Neusa Maria. Alto Uruguai: migração forçada e reatualização da identidade camponesa. Travessia, São Paulo, Ano II, n 6 , jan-abr, 1990, p. 29-32.

SCHUTZ, Alfred. Fenomenologia e relações sociais. Rio de Janeiro: Zahar, 1979.

VAINER, Carlos B. O conceito de "Atingido": uma revisão do debate. In: ROTHMAN, Franklin Daniel (Org.). Vidas alagadas: conflitos socioambientais, licenciamento e barragens. Viçosa-MG: UFV, 2008. pp. 39-63.

VAINER, Carlos B. O conceito de atingido: Uma revisão do debate e diretrizes. In: CARRIZO, Cecilia; BERGER, Mauricio (Orgs.). Justicia ambiental y creatividad democrática. Córdoba: Alción, 2012, pp. 95-118.

WOLF, Eric R. Aspectos das relações de grupos em uma sociedade complexa. In: FELDMANBIANCO, Bela; RIBEIRO, Gustavo Lins (Orgs.). Antropologia e poder: contribuições de Eric R. Wolf. Brasília: UNB: São Paulo: Imprensa Oficia do Estado de São Paulo: UNICAMP, 2003. pp. 73-91. 